\title{
Effective Social Marketing Campaign Can Promote Family Medicine Clinics Utilization: An Intervention Trial
}

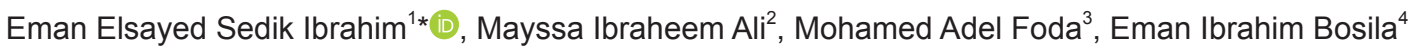 \\ ${ }^{1}$ Department of Family Medicine, Faculty of Medicine, Cairo University, Giza, Egypt; ${ }^{2}$ Department of Internal Medicine, Faculty \\ of Medicine, Cairo University, Giza, Egypt; ${ }^{3}$ Department of Public Health and Community Medicine, Faculty of Medicine, Zagazig \\ University, Zagazig, Egypt; ${ }^{4}$ Department of Family Medicine, Ministry of Health and Population, Cairo, Egypt
} Edited by: Sasho Stoleski
Citation: Ibrahim EES, Ali MI, Foda MA, Bosila EI. Effective Social Marketing Campaign Can Promote Family Medicine Clinics Utilization: An Intervention Trial. Ope AccessMacedJMedSci.2021 Jul 16;9(E):614-619.https://doi org/10.3889/oamjms.2021.647 Keywords: Social marketing; Utilization; Family medicin Department of Family Medicine, Faculty of Medicine. Department of Family Medicine, Faculty of Medicine, E-mail: emanelsayed@kasralainy.edu.e Received: 20-May-202 Revised: 04-Jun-202 Copyright: @ 2021 Eman Elsayed Sedik Ibrahim Mayssa Ibraheem Ali, Mohamed Adel Foda, Funding: This research did not receive any financial Competing Interests: The authors have declared that no competing interests exist Open Access: This is an open-access article distribute under the terms of the Creative Commons AttributionNonCommercial 4.0 International License (CC BY-NC 4.0)

\section{Introduction}

Primary health care $(\mathrm{PHC}) /$ Family medicine is the main part of the health care system worldwide serving as the first contact with the health care system and sharing the other disciplines to provide a comprehensive care including preventive and curative services for the whole family [1]. It is a broad specialty that provides an integrated instead of fragmented health care, putting the biopsychosocial approach a priority to treat the person not only the disease [2]. Unfortunately, the Egyptian health sector provides the medical service through the Ministry of health $(\mathrm{MOH})$ hospitals, University hospitals, Health Insurance Organizations, and the private sector, limiting the use of the free public $\mathrm{PHC}$ sector to only routine services as the compulsory children vaccination [3]. This may be contributed to many reasons as the size of the health facility, the type of provided services, and the longer working hours giving the hospitals the upper hand to attract moreover health centers [4]. Although the $\mathrm{MOH}$ is operating 4,506 PHC facilities distributed all over the country [3] the quality of the public health services has been issued as a problem in most reviews of the Egyptian health care system due to lack of resources, low treatment standards, and rapid turnover of physicians causing underutilization where $65 \%$ of patients receive management with the private health care providers [5].

Until the stakeholders find strategies to improve the public health sector service quality, the awareness about the already available services at the PHC centers may be improved through social marketing as it moves beyond just informing, to influencing the behavior of individuals and the whole communities [6] unlike commercial marketing which seeks the benefit of the marketer [7]. Social marketing was previously applied in Egypt in the 80s and succeeded to increase the use of oral rehydration therapy and contraceptive methods, however, currently social campaigns decreased markedly [8].

The aim of this study is to assess the causes of underutilization of family medicine clinics (FMC) services and to assess the efficacy of a social marketing campaign in promoting the utilization of the FMC services at Hadek AlKobba Family health center (FHC). 


\section{Subjects and Methods}

\section{Study design}

This is an experimental study (community trial) in the form of a social marketing campaign, through three phases, the first and third phases were pre and post-campaign to detect the rate of utilization of the FMC services and the causes of their underutilization. The second phase was a tailored social marketing campaign using the marketing mix which includes " $8 \mathrm{Ps}$ " to formulate the content of the marketing campaign, demonstrated in Table 1 [9].

Table 1: The marketing mix "8Ps"

\begin{tabular}{|c|c|}
\hline Product & $\begin{array}{l}\text { Hadaek AI Kobba FMC services are accessible, affordable, acceptable, } \\
\text { available on daily basis, and provide preventive and curative services for } \\
\text { single and follow-up visits }\end{array}$ \\
\hline Price & $\begin{array}{l}\text { Hadaek AI Kobba FMC services save money, time, and effort as the } \\
\text { consumer can obtain more than one service during a single visit }\end{array}$ \\
\hline Promotion & $\begin{array}{l}\text { The campaign will be promoted through printed promotional materials, } \\
\text { face-to-face communication, and powerpoint presentations }\end{array}$ \\
\hline Place & $\begin{array}{l}\text { Hadek Al Kobba health center and the surrounding catchment area as } \\
\text { the youth club }\end{array}$ \\
\hline People & $\begin{array}{l}\text { The first target audience are all the family members. The second target } \\
\text { audiences include managers of schools and social clubs, and health care } \\
\text { providers including doctors, nurses, and community out-reach workers }\end{array}$ \\
\hline Positioning & $\begin{array}{l}\text { The campaign should emphasize the benefits of FMC services over the } \\
\text { alternative services }\end{array}$ \\
\hline Partnership & Hadek AlKobba Health District could be a partner \\
\hline Purse string & The promotional materials used in the campaign are self-funded \\
\hline
\end{tabular}

\section{Study setting}

This study was conducted at one of the FHCs in Cairo which is at Hadaek Al Kobba district. Hadaek Al Kobba is the biggest FHC in the district with the highest population flow. It is working since 1995, accredited in 2009 with an accreditation score $77.5 \%$, and reaccredited according to data of Hadaek Al Kobba Health District in 2015. The center serves 1100235 citizens and 27000 families. The building consists of four levels. Hadaek Al Kobba Health District takes the third and fourth levels while Hadaek Al Kobba FHC takes the first and second levels, with 2 FMC.

\section{Study subjects}

All the adults attending the FMC were approached to share in the study. The excluded participants were those with critical illness, $<18$ years old and not living at HadaekAI Kobba district. The study participants during the pre and post-campaign period were chosen through random sampling technique. The sample size was calculated by comparing the mean percent of FMC service utilization before and after the campaign. It was done using paired t-test for matched samples. $\alpha$-error level was fixed at 0.05 and the power was $80 \%$. Using previous results, the mean \pm SD of percent of FMC service utilization before the intervention was reported to be $2.6 \pm 1$, while after intervention it was $6 \pm 0.26$ making a difference of
$3.4 \%$. Accordingly, the minimum sample size was 272 FMC attendees for pre-and post-campaign. The resulted sample was doubled to avoid the error of cluster sampling. So, the final sample size was 544 for each group to reach the study objectives. Calculations were done using PS Power and Sample Size Calculations Software, version 3.0.11 for Microsoft Windows [10].

\section{Data collection tools}

- A structured anonymous questionnaire [11] was used to obtain the data from the clinic's non/partial attendees who never came to the FMC or coming irregularly (once every 3 months) to find the causes of underutilization of clinics services. The questionnaire was closed-ended, precoded, and prepared in the Arabic Language to make sure that it is understandable by the participants. It was proved to be reliable through Alpha Cronbach test with value 0.73

Services output indicators from the documented service statistics for percent utilization of outpatient clinic belonging to Hadek AlKobba FHC - after securing official permissions - before, during, and after the campaign. Statistics included patient flow and filing were used.

\section{Study fieldwork}

Along 9 months from January 2016 to

\section{September 2016 as follows:}

- $\quad$ The first phase from January 2016 to March 2016 and included reviewing Hadek AlKobba FHC health records to calculate the service output indicators before the campaign and filling the questionnaire

- The second phase was implementing the social marketing campaign from April 2016 to June 2016, during which seminars were held as internal seminar once weekly at the FHC for the attendees and the workers in the center and external seminars twice monthly in the major gathering areas at Hadaek Al Kobba district as the youth club, three surrounding schools, and the public transportation parking. The total number of seminars internal and external was 12 and 6 , respectively. The social marketing was done through the dissemination of promotional materials including posters, fliers, brochures, mugs, and t-shirts as well as face-to-face communication and powerpoint presentations. The key message that was delivered during the campaign was highlighting the services provided by the FMC at Hadaek Al Kobba FHC 
The third phase was testing the efficacy of the social marketing campaign from July 2016 to September 2016 and included calculating the services output indicators and filling the same questionnaire used before the campaign.

\section{Data analysis}

All questionnaires were revised for completeness and logical consistency. Data were statistically described in terms of mean \pm standard deviation (SD), or frequencies and percentages. Comparison of numerical variables between the study groups was done using Student t-test. $p<0.05$ was considered statistically significant. All statistical calculations were done using computer program the statistical package of social science software program, SPSS release 22 for Microsoft Windows.

\section{Ethical consideration}

The study protocol was approved by the Family medicine department, Faculty of medicine Cairo University council in September 2014 and approved by the Research Committee of the faculty in October 2014 as well as the Ethical Committee in the $\mathrm{MOH}$ in November 2014. An informed verbal consent was also obtained from every participant before filling the questionnaires. They were reassured about the strict confidentiality of any obtained information and that the results would be used only for research purposes.

\section{Results}

Table 2 shows the socio-demographic data of the studied groups $(n=1120)$. The study included

Table 2: The sociodemographic characteristics of the study groups $(n=1120)$

\begin{tabular}{|c|c|c|c|c|c|c|c|c|c|c|}
\hline \multirow[t]{2}{*}{ Variables } & \multicolumn{4}{|c|}{ Regular attenders } & \multirow{2}{*}{$\begin{array}{l}\mathrm{p}- \\
\text { value }\end{array}$} & \multicolumn{4}{|c|}{ Partial/non users } & \multirow[t]{2}{*}{$\overline{p-\text { value }}$} \\
\hline & \multicolumn{2}{|c|}{$\begin{array}{l}(n= \\
460)\end{array}$} & \multicolumn{2}{|c|}{$\begin{array}{l}(n= \\
450)\end{array}$} & & \multirow[t]{2}{*}{$=98)$} & \multirow[t]{2}{*}{$\%$} & \multicolumn{2}{|c|}{$\begin{array}{l}\text { Post (n \% } \\
=112)\end{array}$} & \\
\hline \multicolumn{9}{|l|}{ Gender } & & \\
\hline Male & 77 & 16.7 & 88 & 19.6 & 0.27 & 13 & 13.2 & 17 & 15.2 & 0.512 \\
\hline Female & 383 & 83.3 & 362 & 80.4 & & 85 & 86.7 & 95 & 84.8 & \\
\hline \multicolumn{11}{|l|}{ Age } \\
\hline $18-39$ & 215 & 46.7 & 201 & 44.7 & 0.162 & 64 & 65.4 & 48 & 42.9 & $0.001 *$ \\
\hline $40-59$ & 175 & 38 & 159 & 35.3 & & 30 & 30.5 & 62 & 55.3 & \\
\hline $60->80$ & 70 & 15.3 & 90 & 20 & & 4 & 4.1 & 2 & 1.8 & \\
\hline Mean \pm SD & \multirow{2}{*}{\multicolumn{2}{|c|}{$42.9 \pm 14.3$}} & \multirow{2}{*}{\multicolumn{2}{|c|}{$44.9 \pm 15.5$}} & $0.043 *$ & \multirow{2}{*}{\multicolumn{2}{|c|}{$39.7 \pm 10.7$}} & \multicolumn{2}{|c|}{$37.8 \pm 10.7$} & 0.2007 \\
\hline \multicolumn{5}{|l|}{ Education } & & & & & & \\
\hline High & 20 & 4.3 & 28 & 6.2 & $0.012 *$ & 13 & 13.3 & 8 & 7.1 & 0.118 \\
\hline Intermediate & 124 & 27 & 86 & 19.1 & & 33 & 33.7 & 30 & 26.8 & \\
\hline Illiterate & 316 & 68.7 & 336 & 74.7 & & 52 & 53 & 74 & 66.1 & \\
\hline \multicolumn{11}{|l|}{ Occupation } \\
\hline Work & 47 & 10.2 & 48 & 10.7 & 0.82 & 10 & 10.2 & 23 & 20.5 & $0.017 *$ \\
\hline Non worker & 396 & 86.1 & 382 & 84.9 & & 80 & 81.6 & 87 & 77.7 & \\
\hline Student & 17 & 3.7 & 20 & 4.4 & & 8 & 8.3 & 2 & 1.8 & \\
\hline
\end{tabular}

558 participants during the pre-campaign period, 98 of them were partial/nonusers. About 562 participants were included during the post-campaign period 112 of them were partial/nonusers. Most of the participants were females, illiterate, and non-workers. There was statistical significance in the education of the regular attenders and in the age and occupation of the partial/ nonuser group.

(Figure 1) displays the most important causes of underutilization of services provided by family medicine clinics among non/partial users (pre-and postcampaign) where the most common cause was ignoring about the presence of service $94.9 \%$ which decreased post-campaign to be $75.9 \%$.

Figure 2 shows the common causes of service dissatisfaction provided by the family medicine clinics pre-and post-campaign among non/partial users where the commonest cause was lack of lab investigations and other equipment.

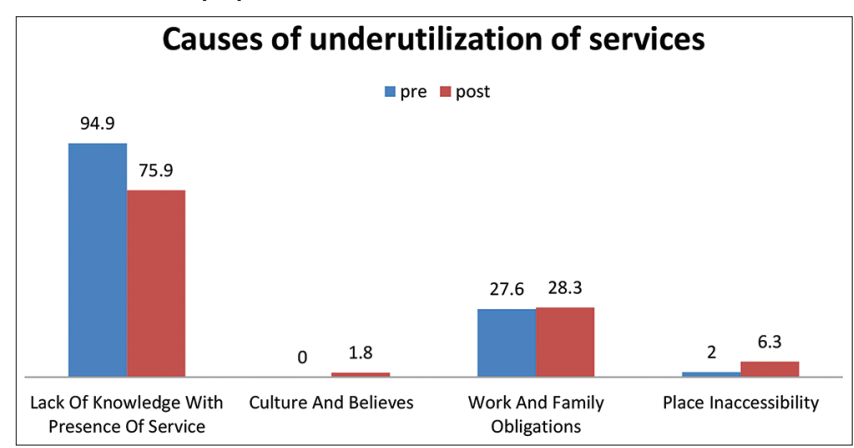

Figure 1: Causes of underutilization of services provided by family medicine clinics among nonuser or partial users (pre and post campaign)

Figure 3 shows that the flow number of the regular attenders of the family medicine clinics from the clinics service records of the 3 months after campaign had lower level than before campaign and September showed re-elevation of the flow while for the new patients attending the family medicine clinics, the records show increase from 61 pre-campaign to 2093 post-campaign.

Figure 4 shows that the number of files opened from the service records, the 3 months after campaign showed an improvement where the follow-up visits increased by $32 \%$ and new files opened increased by $56 \%$.

Table 3 shows that only new patients were significantly increased over time, it was the most

Table 3: Time trend analysis over 6 months in year 2016

\begin{tabular}{|c|c|c|c|}
\hline $\begin{array}{l}\text { Patient and files } \\
\text { variables }\end{array}$ & Number Change per month & Standardized Coefficients & $p$-value \\
\hline $\begin{array}{l}\text { Number of regular } \\
\text { attenders }\end{array}$ & -0.004 & -0.529 & 0.281 \\
\hline $\begin{array}{l}\text { Number of New } \\
\text { commers }\end{array}$ & $0.007 *$ & $0.851 *$ & $0.031 *$ \\
\hline Number of New files & 1.226 & 0.769 & 0.074 \\
\hline $\begin{array}{l}\text { Number of Follow } \\
\text { Up files }\end{array}$ & 0.089 & 0.311 & 0.549 \\
\hline
\end{tabular}




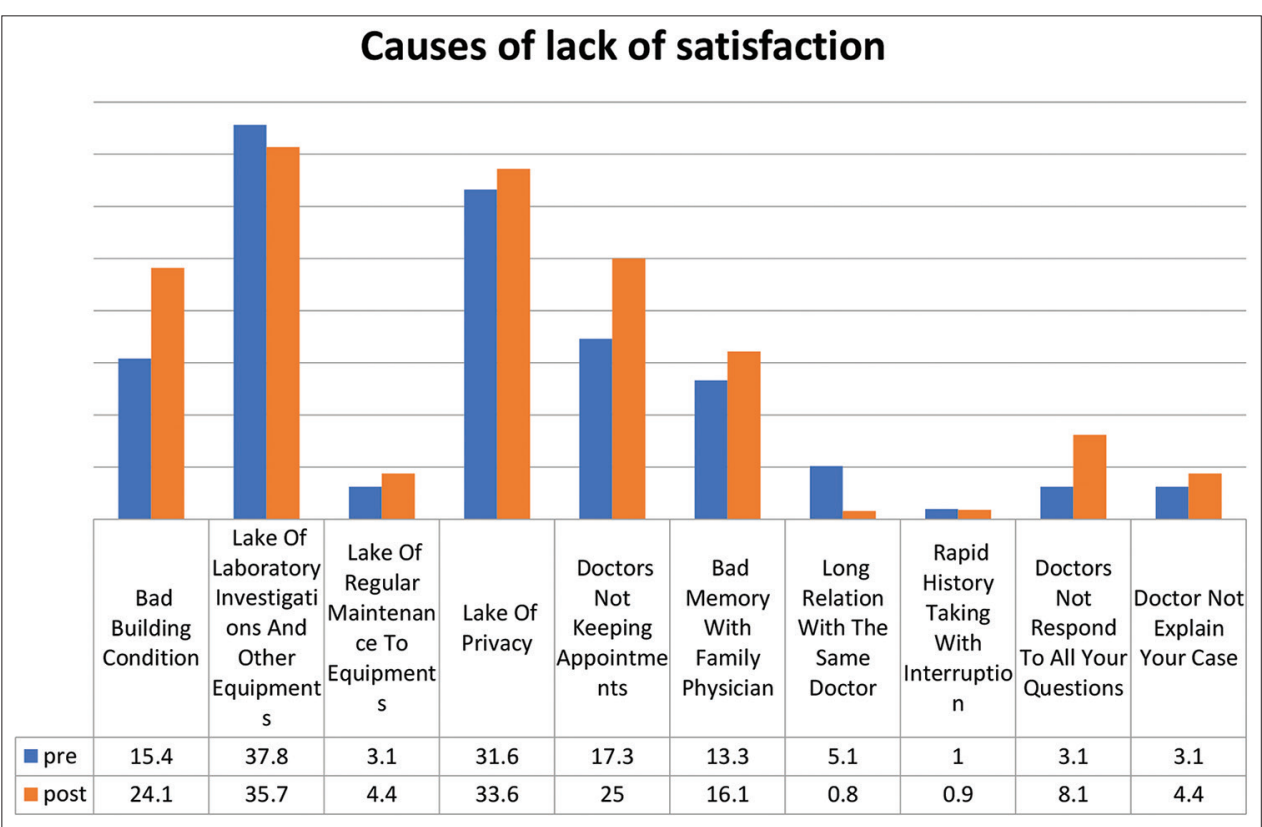

Figure 2: Causes of lack of satisfaction provided by family medicine clinics among nonuser or partial users (pre and post campaign)

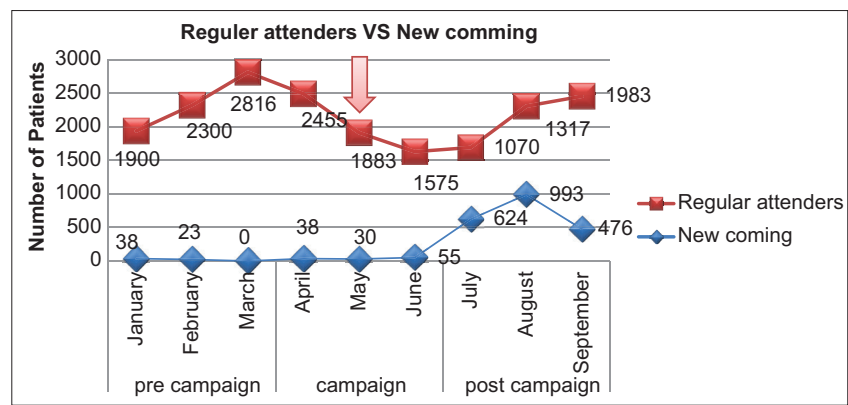

Figure 3: The number of patients attending family medicine clinics at Hadaek Al Kobba family health center

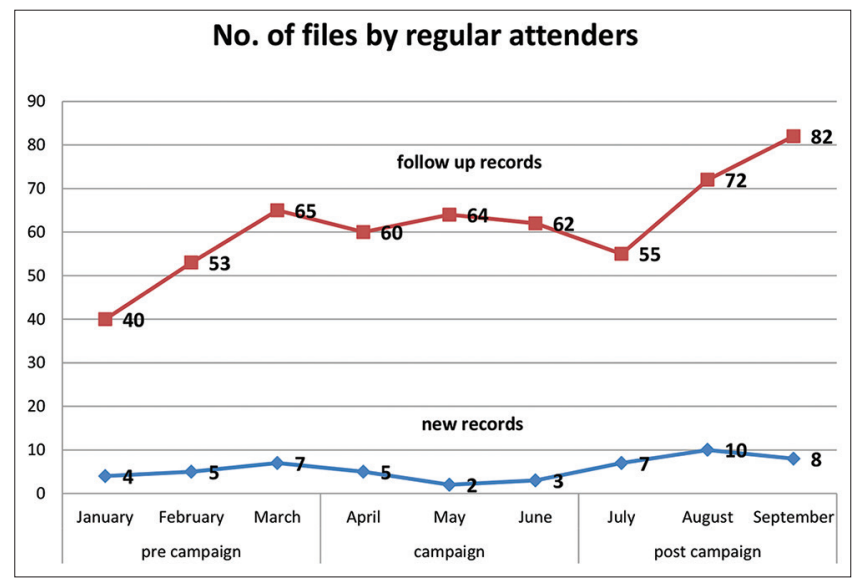

Figure 4: The number of the new and follow up files opened for the attender of the family medicine clinics before, during and after campaign

important one of them because it was standardized coefficient and it was more than all of them. Approximately there was one patient increased every month because some months were lower in number and others were fixed.

\section{Discussion}

Although it is well established that Family physicians/general practitioners have been the basis of providing PHC services in many developed and developing countries, in Egypt, the situation is still different mostly due to the negative attitude towards the family physicians as well as the PHC centers as unqualified and unreliable [12]. Social marketing can be used as an effective approach to increase people's awareness and change their attitude and behaviors related to the prevention and control of diseases and hence increasing utilization about specific specialties such as family medicine [6].

Social marketers conduct formative process, and evaluative research to discover barriers to behavioral change and develop approaches that address them [13]. This study is conducted to assess the efficacy of social marketing campaigns in increasing the utilization rate of FMC services at Hadek Alkoba FHC.

The study revealed that the most important cause of underutilization was lake of knowledge about the presence of the service $(94.9 \%)$ so part of the campaign success was increasing the awareness of the served community with the presence of the FMC services in the center, this is unlike (El-Seifi et al., 2009) who found that lack of satisfaction among household non-users of FHC units in Sharkia Governorate was mainly due to shortage or absence of advanced drugs causing them to buy from the more expensive private pharmacies [14].

The study revealed that the most causes of service dissatisfaction provided by FMC were related to 
infrastructure and doctors' performance which are out of control of researcher and the commonest cause was lack of laboratory investigations and other equipment $(37.8 \%)$ and here came the role of HadeK Al Kobba Health District which was a partner in the campaign through solving some of these problems such as improvement of the building and doctors' performance (like not keeping appointments) and following the regular maintenance of the center equipment's through all the period of implementation of the campaign. Unlike Alhashem et al. 2011 who concluded that the majority $(87 \%)$ of patient's dissatisfaction was related to lack of enough time for communication between physician and patient [15].

The social marketing campaign was able to increase the flow number of the new patients attending FMC, the number of new family files opened and the frequency of weekly visits of regular attenders post-campaign than its number precampaign this is similar to Ghobashi et al., 2013 who concluded that service output indicators after social marketing campaign had improved and become more than before the campaign [11].

The study revealed that social marketing campaign can improve service utilization of FMC, This result got in agreement with many other studies that revealed that social marketing had been successful to improve the use of a variety of products, including birth control pills, oral rehydration salts, breastfeeding, and the consumption of multivitamin and mineral supplements [16].

\section{Limitations of the study}

- $\quad$ The small number of available working family physicians affected service performance and the client did not find beneficiaries desired services after campaign as they were told

- During the campaign period, there were Ramadan and many official vacations which affect the flow rate for people attending the center

- $\quad$ More service output indicators should be used to evaluate the services provided by the $\mathrm{FHC}$ clinic services.

\section{Conclusion}

Social marketing is an effective intervention to promote the utilization of the services provided by FMC by increasing the flow rate of the new attenders to the FHC and subsequently the frequency of visits to the FMC and the utilization of the follow-up records.

\section{References}

1. Rakel R. Principles of family medicine-the family physician. In: Rakel R, Rakel D, editors. Textbook of Family Medicine. $9^{\text {th }}$ ed. Philadelphia, PA: Elsevier Inc.; 2016. p. 3-16. https://doi. org/10.1016/b978-1-4377-1160-8.10001-6

2. AAFP. The Specialty of Family Medicine. Family Medicine: The Center of Primary Care. Available from: http://www.aafp.org/ about/the-aafp/family-medicine-specialty.html. [Last accessed on 2021 May 10]. https://doi.org/10.1370/afm.2546

3. Egypt Service Provision Assessment Survey. Overview of the health system in Egypt. In: Analysis and Reform Program. Ch. 2. Cairo, Egypt: MOHP; 2002. p. 13-9. Available from: http:// www.dhsprogram.com/pubs/pdf/SPA5. [Last accessed on 2021 Feb 20].

4. Baker JB, Lin L. The determinants of primary health care utilization: A comparison of three rural clinics in southern Honduras. Gen J. 2006;66(4):295-310. https://doi.org/10.1007/ s10708-006-9001-8

5. Al Bahnasy Rabei A, Mohamed Omaima A, El-Shazly Hewida A, Abdel-Azeem Azza A, Khedr Rasha M. The successes and the challenges of Egyptian health sector reform program. Menoufia Med J. 2016;29(4):979-83

6. ECDC. European Centre for Disease Prevention and Control, Social Marketing Guide for Public Health Programme Managers and Practitioners; 2014. Available from: http://www.ecdc. europa.eu/./publications/Publications/social-marketing-guidepubli. [Last accessed on $2021 \mathrm{Apr} 10]$.

7. Holt C, Fawcett S, Francisco V, Schultz J, Berkowitz B, Wolff T. Why is Social Marketing Important? The Community Tool Box is a Public Service of the University of Kansas. Ch. 45. Kansas: University of Kansas; 2017. Available from: http://www. ctb.ku.edu/en/sustain/social-marketing/overview/main. [Last accessed on 2021 Apr 15].

8. PSI. What Is Social Marketing? Social Marketing and Communications for Health; 2003. Available from: http://www. psi.org. [Last accessed on 2021 Apr 15].

9. Martin: 7Ps of Marketing, Additional Elements of Marketing Mix-Cleverism; 2014. Available from: https://www.cleverism. com/7ps-additional-aspects-marketing-mix. [Last accessed on 2021 Jan 08]. https://doi.org/10.18502/kss.v3i13.4235

10. Dupton W, Plummer W. PS: Power and Sample Size Calculation Version 3.1.2; 2014. Available from: http://www.biostat. mc.vanderbilt.edu/wiki/bin/view/Main/PowerSampleSize. [Last accessed 2016 Jan 12].

11. Ghobashi M, Fouda M, Khafagy G, Saied R. Effect of social marketing campaign on utilization of primary health care services in urban sector of Sharkia governorate. Zagazig Univ Med J. 2014;20(6):1-10. https://doi.org/10.21608/zumj.2017.4443

12. Metwally D. Patients' satisfaction with primary health care in Egypt: Exploring the gap between rural and urban governorates. J Soc Dev Sci. 2014;5(4):221-30. https://doi.org/10.22610/jsds. v5i4.821

13. NSMC. Social Marketing Benchmark Criteria; 2010. Available from: http://www.nsmcentre.org.uk. [Last accessed on 2021 Mar 11].

14. El-Seifi OS, Wassif S, Koura S. Health profile of Sharkia 
governorate: An epidemiological study. Zagazig Univ Med J. 2009;15(2):2357-717.

15. Alhashem AM, Alquraini $\mathrm{H}$, Chowdhury RI. Factors influencing patient satisfaction in primary healthcare clinics in Kuwait Int J Health Care Qual Assur. 2011;24(3):249-62. https://doi. org/10.1108/09526861111116688

\section{PMid:21938970}

16. Talbert YP. Using social marketing to increase breast cancer screening among African American women: Perspectives from African American breast cancer survivors. Int J Nonprofit Volunt Sect Mark. 2008;13:347-62. https://doi.org/10.1002/ nvsm. 345 